\title{
Advanced method of managing soil conservation works in Smart Farms
}

\author{
Eugen Marin ${ }^{1, *}$, Marinela Mateescu ${ }^{1}$, and Carmen Bălțatu ${ }^{1}$ \\ ${ }^{1}$ National Institute of Research-Development for Machines and Installations designed to Agriculture \\ and Food Industry-INMA Bucharest 013813, Romania
}

\begin{abstract}
The paper presents the results obtained in the SMART farm by using an advanced method of managing soil conservation works. These works involve, first of all, the collection and storage of data on the spot regarding the following parameters in which the plants will grow: disease climate (air temperature, dew point), growth climate (air temperature, solar radiation, deficiency vapours pressure, relative air humidity, precipitation, wind speed, maximum wind speed, daily evaporation) and soil monitoring (soil moisture, precipitation, soil salinity, soil temperature). Data collection is done through intelligent sensors from a wireless weather station and the reception of this information in real-time on a computer/smartphone by the farmer. Therefore, the farmer will be able to make instant decisions on soil conservation work, thusly saving time and workforce for additional on farm inspections.
\end{abstract}

\section{Introduction}

International agricultural research could make important contributions to increasing production and making the most rational use of existing resources [1].

The declining availability of agricultural land, ecological losses and environmental degradation are leading to the adoption and diffusion of digital agricultural technologies that contribute to the transformation of current agricultural systems towards sustainability [2], [3], [4], [5].

Farmers are increasingly determined to implement smart solutions where agricultural technologies are digitally monitored and each agricultural work is managed with the help of IT systems, applications specially developed for agricultural activity [6].

Smart farming involves, among other things, real-time management of meteorological information on a farm to maximize agricultural production. Wireless weather stations are important tools for monitoring the soil (soil moisture, precipitation, soil salinity, soil temperature) within a farm, as many of the problems related to agricultural activity can be solved by a better understanding of the surrounding weather conditions [7].

The iMETOS 3.3 station is designed for all types of environmental conditions, has non-volatile memory, communicates and transmits real-time weather information via GSM [8].

\footnotetext{
* Corresponding author: marin 43eu@yahoo.com
} 


\section{Material and Methodology}

An experimental model of an innovative soil conservation system for SMART farm was developed within INMA Bucharest. This system uses an advanced management method that involves collecting and storing on-site data on soil monitoring (soil moisture, precipitation, soil salinity, soil temperature) via an iMETOS 3.3 wireless weather station. The weather station is equipped with high quality sensors, a datalogger and a GPRS system for uploading data regularly on the FieldClimate by Pessl Instruments platform. The agrometeorological information transmitted on the internet platform and communications of Pessl Instruments were downloaded, interpreted and analysed from any place with internet access at any time, in real-time on desktop or mobile phone, by researchers for instant decision making, saving time and manpower for the necessary field checks [7].

Aspects of the configuration of the iMETOS 3.3 wireless weather station, located in the experimental field of INMA Bucharest and viewed on the FieldClimate by Pessl Instruments platform on the desktop or on the mobile phone are presented in figure 1.
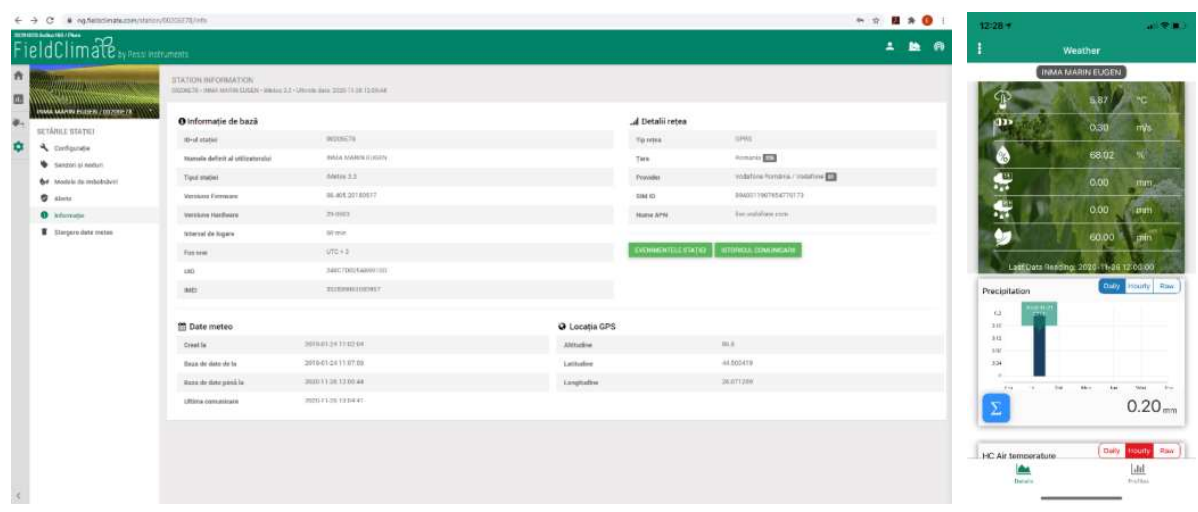

Fig. 1. Aspects of the configuration of the iMETOS 3.3 wireless weather station viewed on the FieldClimate by Pessl Instruments platform on the desktop or on the mobile phone

The access to the weather station data was made from the platform www.fieldclimate.com, from where it was possible to configure and SMS alerts for different parameters measured by the iMETOS 3.3. The FieldClimate platform is designed by Pessl Instruments for collecting, analysing, displaying agronomic, meteorological, soil, insect and tracking data (Fig. 2) by integrating field climatic data that are collected from all Metos-type climate stations [9].

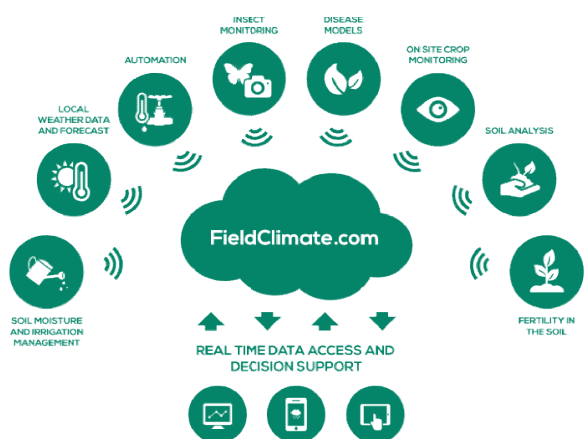

Fig. 2. Holistic Solutions for Decision Agriculture, Supported Through FieldClimate 
Using the remote data exchange (field office) the researchers were able to inform the operator (mechanizer) when to prepare the tillage equipment in the arable substrate adapted to the conservative technology.

An Agrotron X720 tractor was used to carry out experimental research in field conditions, in order to determine the qualitative work and energy indices of the conservation tillage technology. The tractor has the following main technical characteristics: overall dimensions (length $\times$ width $\times$ height), mm: $5399 \times 2749 \times 3270$; tractor mass, kg: 9995; wheelbase, mm: 3095; front / rear axle track, mm: 2104/2014; engine power: $198 \mathrm{~kW}(269 \mathrm{hp})$ [11].

The application of the conservative tillage technology was made with the tillage equipment in the arable substrate adapted to the conservative technology (fig. 3), which is of the type carried on the three-point suspension mechanism mounted on the back of the 220- wheel tractors. $240 \mathrm{CP}$, category 3, SR ISO 730: 2012 [12].

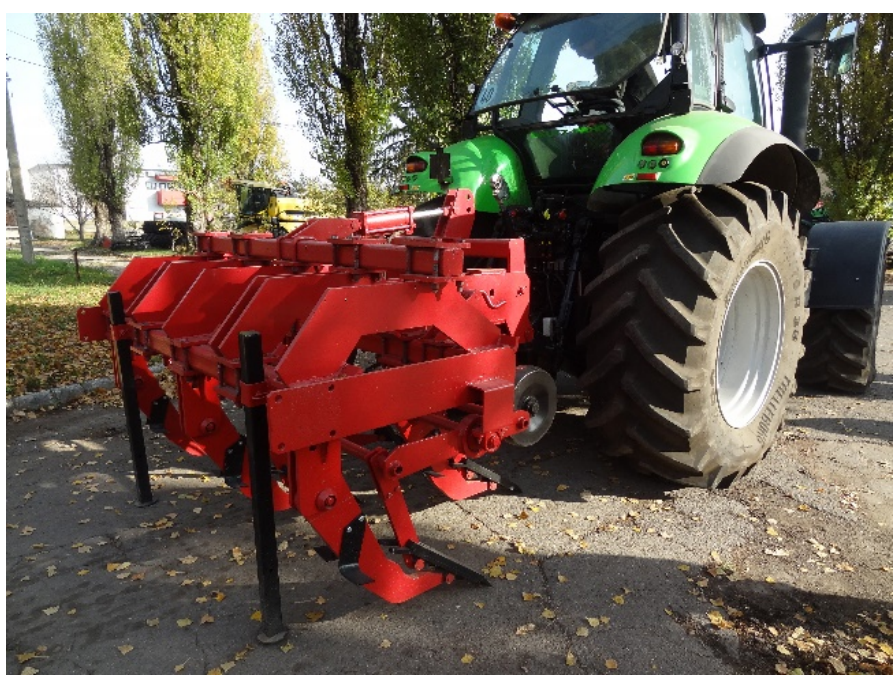

Fig. 3. Tillage equipment in arable substrate adapted to conservative technology

The main technical characteristics of tillage equipment in the arable substrate are presented in Table 1.

Table 1. The main technical characteristics of tillage equipment in the arable substrate

\begin{tabular}{|l|c|c|}
\hline \multicolumn{1}{|c|}{ Characteristic } & U.M & Value \\
\hline Operation source & $\mathrm{kW}(\mathrm{CP})$ & $161 \ldots 176(220 \ldots 240)$ \\
\hline Number of loosening organs & pieces & 5 \\
\hline Maximum working depth & $\mathrm{cm}$ & 60 \\
\hline Working width & $\mathrm{m}$ & 2,3 \\
\hline Mass & $\mathrm{kg}$ & 1800 \\
\hline
\end{tabular}

The tests were performed on the experimental fields of INMA Bucharest in accordance with a specific test procedure. The additional equipment for determining the soil characteristics in the experimental field were the following:

- Electronic penetrometer with digital cone FIELDSCOUT SC 900;

- Portable soil humidometer type HH2 + ThetaProbe ML2x precision sensor.

During work, to avoid overlaps and replace the landmark, the operator (mechanic) used a guidance system (fig. 4), which consists of a MATRIX ${ }^{\circledR} 570$ GS console, a $26 \mathrm{~dB}$ RXA-30 antenna and a camera RealView with night vision. 

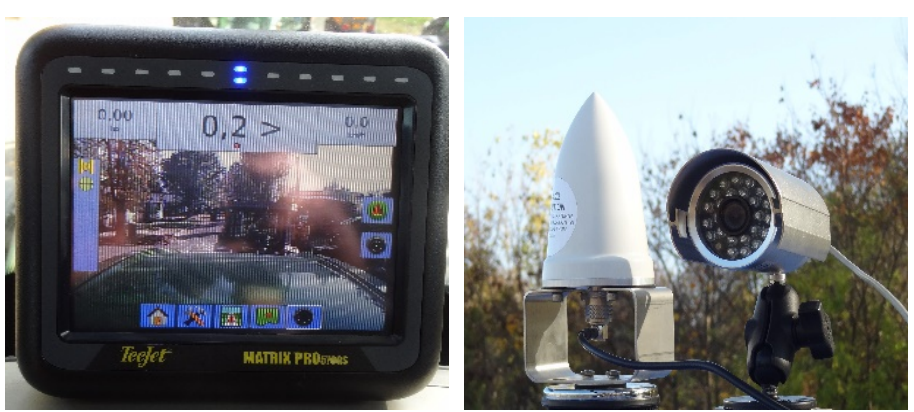

Fig. 4. MATRIX® $570 G S+$ RXA-30 + RealView manual guidance system [13].

One of the main indicators used to determine a wide variety of physical and mechanical properties of the soil is the resistance to penetration. Measurements of penetration resistance were performed with the digital penetrometer, working in 3 repetitions for the experimental group.

Figure 5 shows graphically the average values of the distribution of resistance forces to the penetration of the cone in the soil layers, in $\mathrm{kPa}$, determined in 12 test points up to a maximum depth of $30 \mathrm{~cm}$.

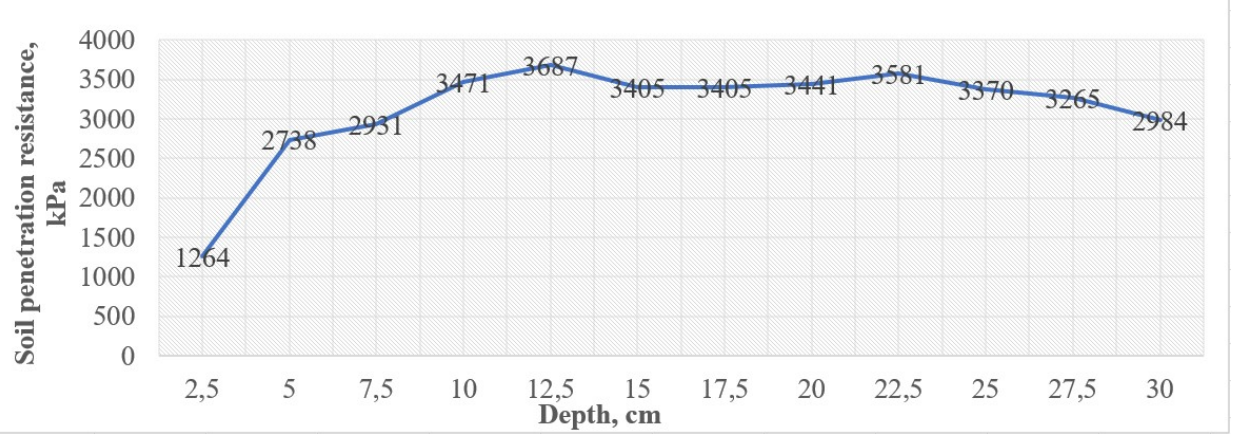

Fig. 5. Graphical representation of the average values of the distribution of resistance forces to the penetration of the cone in the soil layers of the experimental plot

On the experimental group, the water content expressed as a percentage of the soil volume was measured in 3 repetitions using the HH2 portable soil humidometer + ThetaProbe ML2x precision sensor.

Figure 6 shows graphically the average values of soil moisture determined as a percentage of soil volume.

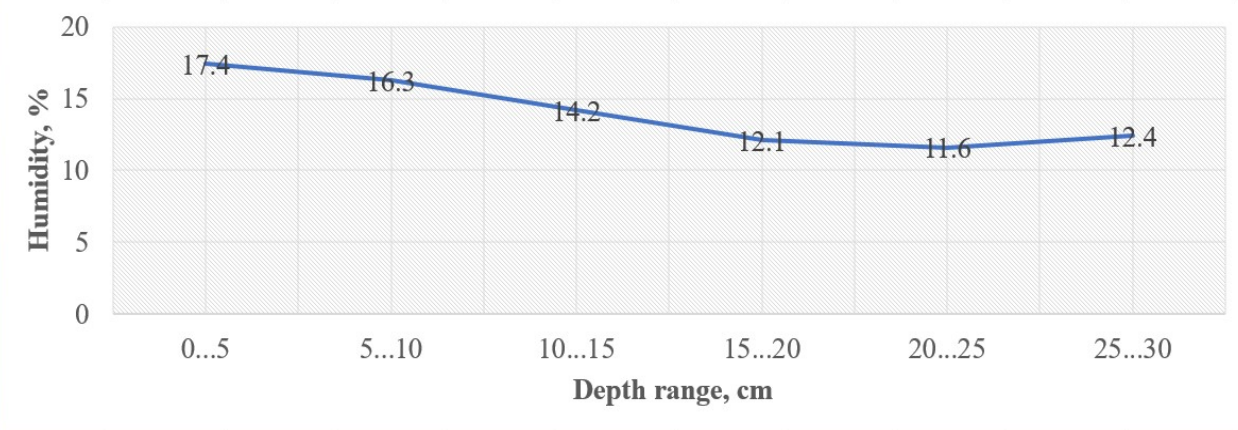

Fig. 6. Graphical representation of the average values of soil moisture on the experimental group 
Given that it has led to a shortage of water in the soil, the conservation of still existing water is a very important thing. Conservative tillage leads to soil consolidation in order to keep the water even at shallow depths.

The iMetos 3.3 weather station allowed to monitor in real time the soil characteristics, by transmitting data on computer / smartphone on: soil moisture [\%], precipitation [mm], soil salinity [VIC], soil temperature $1\left[{ }^{\circ} \mathrm{C}\right]$.

Figure 7 shows graphically the soil monitoring (soil moisture, precipitation, soil salinity, soil temperature) on the experimental group INMA Bucharest.

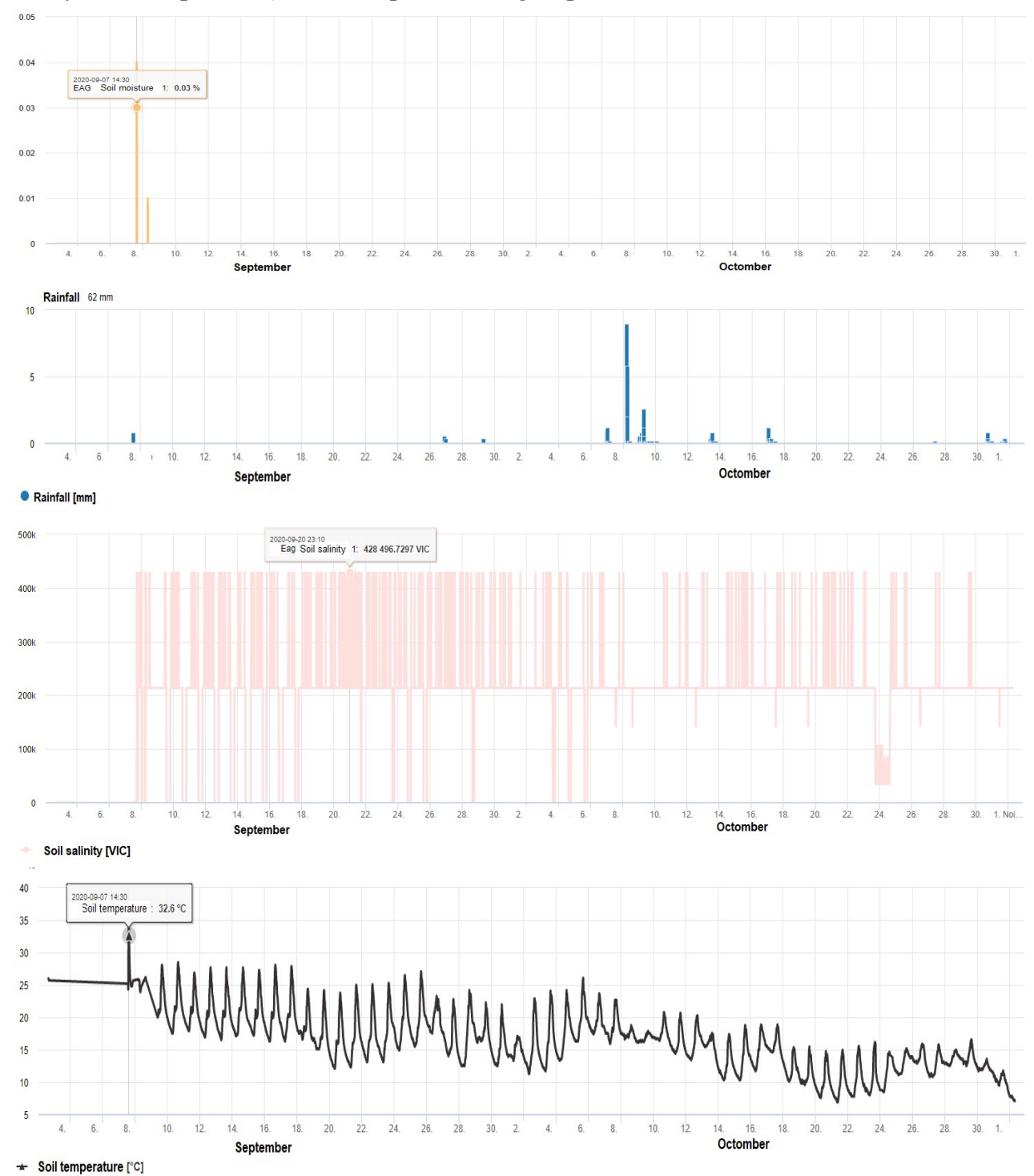

Fig. 7. Diagram regarding soil monitoring on the INMA Bucharest experimental lot

The following quality indicators were determined with the technical equipment in the Agrotron X $720197 \mathrm{~kW}$ (269 hp) tractor unit:

- the variation index of working depth, $\mathrm{V}_{\mathrm{a}}$;

- the variation index of working width, $\mathrm{V}_{\mathrm{b}}$;

- loosening degree, $\mathrm{G}_{a s}$. 
Equations (4), (5), (6), (7), (8), (9) and (10) presented in [14] were used for the calculations:

- Loosening degree was calculated according to the following equation:

$$
G_{a s}=\frac{\sum_{1=1}^{n} \frac{h_{1}-h_{2}}{h 1}}{n},[\%]
$$

where: $h_{l}$ is the ordinate at a certain point on the ruler at the soil surface before the passage of technical equipment $[\mathrm{cm}]$;

$h_{2}$ - the ordinate at the same point on the ruler at the soil surface after the passage of technical equipment $[\mathrm{cm}]$;

$\mathrm{n}$ - number of measurements.

- Average working depth was determined by measuring the distance between soil surface and the bottom of the furrow left by the active body and was calculated according to the following equation:

$$
a_{m}=\frac{\sum_{1=1}^{n} a_{i}}{n},[\mathrm{~cm}]
$$

where $a_{i}$ is the measured working depth, cm and $\mathrm{n}-$ number of measurements.

The standard deviation of working depth was calculated according to the following equation:

$$
\sigma= \pm \sqrt{\frac{\sum_{1=1}^{n}\left(a_{i}-a_{m}\right)^{2}}{n-1},[\mathrm{~cm}]}
$$

The variation index of working depth was calculated according to the following equation:

$$
V_{a}=\frac{\sigma_{a}}{a_{m}} \times 100,[\%]
$$

Average working width was calculated according to the following equation:

$$
B_{m}=\frac{\sum_{i=1}^{n} B_{i}}{n},[\mathrm{~m}]
$$

where: $B_{i}$ is the measured working width, $\mathrm{m}$ and $\mathrm{n}-$ number of measurements.

The standard deviation of working width was calculated according to the following equation:

$$
\sigma= \pm \sqrt{\frac{\sum_{1=1}^{n}\left(B_{i}-B_{m}\right)^{2}}{n-1},[\mathrm{~cm}]}
$$

The variation index of working width was calculated according to the following equation:

$$
V_{B}=\frac{\sigma_{B}}{B_{m}} \times 100,[\%]
$$

Table 2 shows the average values of the qualitative working indices determined following the tests carried out with the tractor unit and the tillage equipment in the arable substrate adapted to the conservative technology.

Table 2. Qualitative work indices

\begin{tabular}{|l|c|c|}
\hline \multicolumn{1}{|c|}{ Qualitative work indices } & U.M & Value \\
\hline The variation index of working depth, $\mathrm{V}_{\mathrm{a}}$ & $\%$ & 1,68 \\
\hline The variation index of working width, $\mathrm{V}_{\mathrm{b}}$ & $\%$ & 1,44 \\
\hline Loosening degree, $\mathrm{G}_{a s}$ & $\%$ & 18,1 \\
\hline
\end{tabular}

Figure 8 shows graphically the variation of the energy indices determined for three speed stages of the unit with the Agrotron X 720 tractor. 


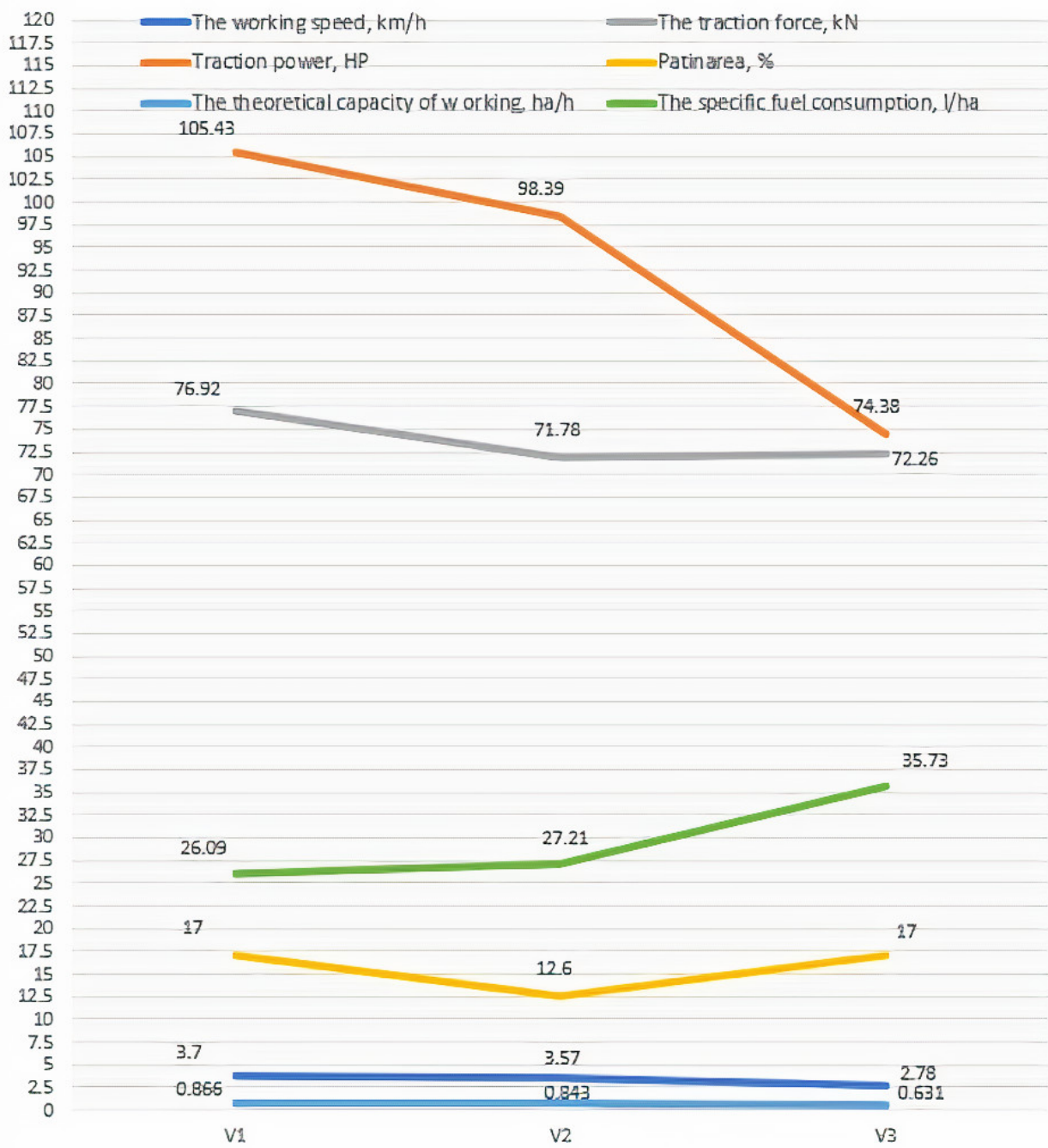

Fig. 8 Graphical representation of the variation of indexes determined for three speed stages

After the experimental tests performed with the technical equipment for soil conservation work, the following obtained results can be presented:

- in terms of operation, the equipment has obtained qualitative work indices that are in accordance with the agro-technical requirements provided for working the soil in the arable substrate, in accordance with the standard in force. This was proved in the variation index of working depth $-1.68 \%$, the variation index of working width $-1.44 \%$ and loosening degree $-18.1 \%$;

- at the tests performed the equipment had a good performance, achieving an average working capacity of $0.778 \mathrm{ha} / \mathrm{h}$ at the real working time in the average working speed of $3.35 \mathrm{~km} / \mathrm{h}$.

\section{Conclusions}


- experimental research has allowed the validation of technical and technological solutions adopted in the design and implementation of the experimental model of innovative system of conservative tillage for SMART farm;

- the results of experimental research allow useful recommendations for farmers who apply innovative system of conservative tillage in order to increase efficiency and ensure efficient soil management for sustainable production.

This work was supported by a grant of the Romanian Ministry of Education and Research, through Programme NUCLEU, ctr. nr. 5N / 07.02.2019, project PN 191002 01-Development of innovative technologies inside of Smart Farms.

\section{References}

1. W. Martin, A research agenda for international agricultural trade. Applied Economic Perspectives and Policy, 40(1), 155-173, (2018)

2. L. Shang, T. Heckelei, M.K. Gerullis, J. Börner, S. Rasch, Adoption and diffusion of digital farming technologies - integrating farm-level evidence and system interaction, Agricultural Systems, Volume 190, (2021)

3. N. Ungureanu, V. Vlăduț, Biriș, FEM modelling soil behaviour under compressive loads, the International Conference of Applied Sciences (ICAS2016), Materials science and engineering, Vol 163 (2017), 012001, pg. 1-9 (2017);

4. L.Vlăduțoiu, P.Cârdei, V.Vlăduț, L. Fechete, Modern trends in designing and selecting the machine/equipment for deep soil tillage, 16th International Scientific Conference Engineering for Rural Development”, pg. 1415-1420, Jelgava, Letonia (2017);

5. N. Ungureanu, V. Vlăduț, S.-Ș. Biriș, G. Paraschiv, M. Dincă, B. Ș.Zăbavă, V. Ștefan, NE Gheorghiță, FEM modelling of machinery induced compaction for the sustainable use of agricultural sandy soils, Proceeding of the 46th International Symposium „Actual Tasks on Agricultural Engineering”, 2018, pg. 201-211 (2018)

6. R. Finger, S.M. Swinton, N. El Benni, A. Walter, Precision farming at the nexus of agricultural production and the environment, Ann. Rev. Resour. Econ., 11 (1) pp. 313 335 (2019)

7. Tenzin, S. Siyang, T. Pobkrut and T. Kerdcharoen, Low cost weather station for climate-smart agriculture, 9th International Conference on Knowledge and Smart Technology (KST), Chonburi, Thailand, 2017, pp. 172-177, (2017)

8. D. Strigaro, M. Cannata, M. Antonovic, Boosting a Weather Monitoring System in Low Income Economies Using Open and Non-Conventional Systems: Data Quality Analysis. Sensor,s 19(5):1185, (2019)

9. V. Neagoe, M. Neagoe, E. Marin, I. Voicea, Contributions to the improvement of technical equipment for soil substratum tillage, adapted to conservation technology, International Symposium, ISB-INMA-TEH, Agricultural and Mechanical Engineering, 605-608, INMA Bucharest (2020)

10. iMetos 3.3 weather station and Field Climate platform - Website https://metos.at/imetos33/; https://metos.at/fieldclimate/; Austria.

11. Tractor Agrotron X 720, website https://www.deutz-fahr.com/eneu/products/tractors/6404-agrotron-x;

12. SR ISO 730:2012, - website https://magazin.asro.ro/ro/standard/200754

13. Agricultural GPS Matrix pro 570GS for tractor, website https://agri-inovatie.ro/ghidajgps-agricol-tractoare/278-matrix-pro-570gs.html

14. Şt. Croitoru, E. Marin, M. Bădescu, V. Vlăduţ, Agrotechnical and energetic characteristics of new designed subsoiler, in Proc. 43rd International Symposium on Agricultural Engineering. Actual Tasks on Agricultural Engineering, pp. 165-176, Opatija, Croatia (2015) 